\title{
Joined-up action for biodiversity
}

\author{
Awaiting the Fifteenth meeting of the Conference of the Parties to the Convention on Biological Diversity (CBD) \\ to be held in China late in 2021, Elizabeth Maruma Mrema, Executive Secretary to the CBD, talks to Nature \\ Sustainability about the challenges of stepping up efforts to address biodiversity decline.
}

\section{Biodiversity is declining worldwide, what role should international law play to help?}

The CBD together with its Protocols and all other biodiversity-related conventions constitute the pillars of international law for conservation and sustainable use of biodiversity. The effectiveness of these treaties depends on the level of commitment and capacity of the parties. Compliance is generally imperfect due to many reasons. It would be very difficult to achieve conservation and sustainability objectives without addressing underlying economic issues such as agriculture expansion, particularly in developing countries. With declining global prices of commodities, poor communities continue to clear forests or convert wetlands to produce more for the international market and so earn hard currency to pay their debts to international lenders. At the level of value chains, international law can help mitigate or reverse biodiversity loss by promoting the mainstreaming of environmental standards and safeguards into investment, trade and economic policies. We need greater integration of policies and standards, and better understanding of existing legal frameworks. Ultimately, we need environmental management systems, supported by international norms, that take due consideration of environmental risk on the one hand, and the vulnerability of social and economic systems on the other. The world needs to change the way it measures economic success. Law is just one of many tools.

The Sustainable Development Goals call for zero hunger, no poverty and conservation of life below water and on land. How do we achieve all that at the same time?

This is a challenge. Hunger, poverty and the continued decline in biodiversity are linked societal challenges. On our current trajectory, biodiversity, and the services it provides, will continue to decline, jeopardizing the achievement of the Sustainable Development Goals, due to the increasing impacts of land- and sea-use change, overexploitation of resources, climate change, pollution and

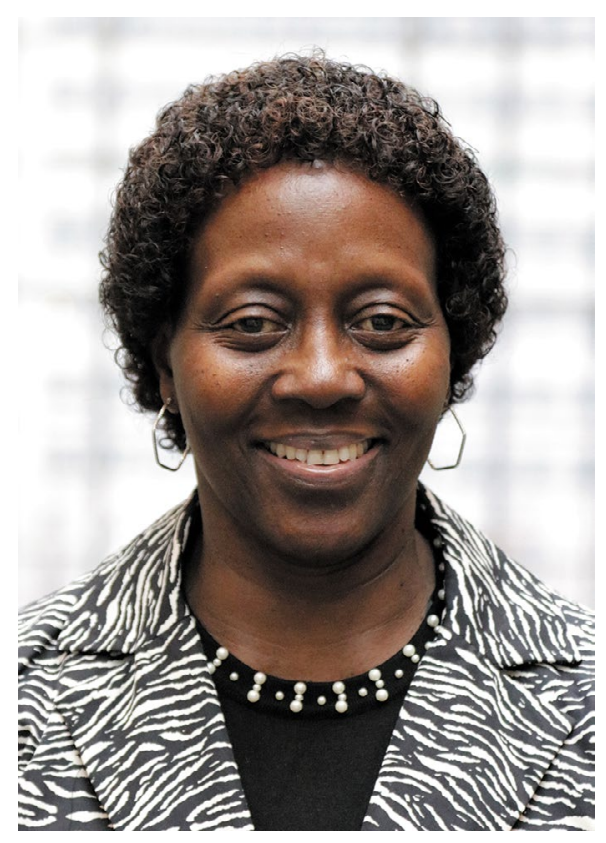

Elizabeth Maruma Mrema.

invasive species - all pressures driven by unsustainable patterns of production and consumption. The projected decline in biodiversity will affect all people, but especially indigenous and local communities, and the world's poor and vulnerable, as they rely on biodiversity for their livelihoods. However, it is not too late to change path. We need a portfolio of actions to address all drivers of biodiversity decline, at all levels, using context-specific approaches; urgent transformations are needed in the production of goods and services, especially food, provision of fresh water, energy and products from forestry. This requires a significant shift away from business-as-usual and a focus on synergies. There is no single pathway ahead but many alternative approaches reflecting local conditions and priorities - flexibility is crucial to tailor measures to national realities and circumstances.

Are there important stakeholders who need a stronger voice in the CBD?

We won't bend the curve of biodiversity loss without a whole-of-society approach.
Governments will have a particularly important enabling role to play but ultimately all stakeholders and actors need to have a stronger voice - a core principle to the post-2020 global biodiversity framework. Historically marginalized indigenous peoples and local communities will need greater opportunities to have their voices heard. Similarly, the role of women and girls in the implementation of the Convention needs to be enhanced as emphasized already in recent decisions of the conference of the parties to the Convention. Partnerships with the private sector can also play an important implementation role even though vested interest might pose some challenges. How do we achieve this? The $\mathrm{CBD}$, among other things, organizes finance workshops to engage the financial sector; we have a specific engagement programme to help businesses participate in the CBD process. We also consult extensively with indigenous peoples and local communities and have always ensured that civil society is engaged. We support youth through our Global Youth Biodiversity Network, and our gender programme of action informs our engagement with women's groups.

What are the key barriers the CBD has to overcome in order to progress with its mandate?

The main barrier is fragmented decision-making and the lack of integrated approaches. Currently biodiversity is not given appropriate consideration in decision-making outside of the environment section and is largely treated as an after-thought in most decision-making and planning processes. We need to move biodiversity from the periphery of decision-making. We also need to remove sectoral silos in order to facilitate integrated decisions and so avoid perverse incentives, which result in subsidizing the destruction of nature rather than its protection, and short-term thinking in decision-making that hinders the achievement of long-term sustainability.

How do you see the multilateral efforts on biodiversity conservation evolving over the next years?

We are likely to see a greater push or emphasis on reaching societal objectives 
in an integrated manner in order to enable real transformations. There is growing recognition that the challenges the world is currently facing are interconnected and addressing them in isolation is neither effective nor realistic. For example, biodiversity will not be conserved if we do not address climate change. Conversely biodiversity offers potential solutions to climate change. Similarly, biodiversity is the basis for our food systems yet the way in which we produce and consume food undermines biodiversity. Likewise, biodiversity is essential to human health but the current pressures on biodiversity erode at the foundations of human health as demonstrated through the ongoing COVID-19 pandemic. I also believe that in the future greater emphasis will be placed on monitoring progress towards international goals and on communicating the results of these efforts. More effective monitoring and communication will be essential to learn from experience and inform decisions. It will also be important in holding all actors accountable for their actions and the commitments they make or agree to.

Interviewed by Monica Contestabile

Published online: 29 April 2021

https://doi.org/10.1038/s41893-021-00717-3 